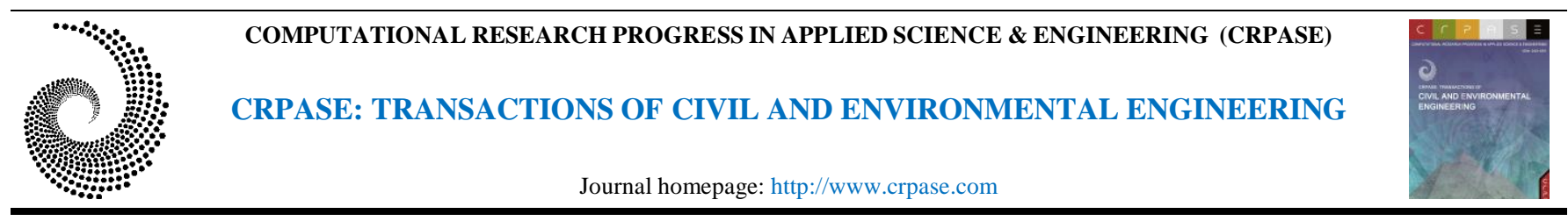

CRPASE: Transactions of Civil and Environmental Engineering 7 (3) Article ID: 2363, 1-5, September 2021

ISSN 2423-4591

Research Article

Check for
updates

\title{
Evaluating Campus Components According To The Inclusive Design Principles Using An Integrated Consistent Fuzzy Preference Relations And Grey Relational Analysis Methodology
}

\author{
Sahika Ozdemir ${ }^{1 *}$, Kemal Gokhan Nalbant ${ }^{2}$, Yavuz Ozdemir ${ }^{3}$ \\ ${ }^{1}$ Department of Interior Architecture and Environmental Design, Istanbul Sabahattin Zaim University, Istanbul, Turkey \\ ${ }^{2}$ Department of Software Engineering, Beykent University, Istanbul, Turkey \\ ${ }^{3}$ Institue of Graduate Education, Istanbul Sabahattin Zaim University, Istanbul, Turkey
}

\begin{tabular}{|c|c|}
\hline Keywords & Abstract \\
\hline $\begin{array}{l}\text { Campus climate, } \\
\text { Inclusive design, } \\
\text { Consistent Fuzzy } \\
\text { Preference Relations } \\
\text { (CFPR), } \\
\text { Grey Relational Analysis } \\
\text { (GRA), } \\
\text { Multi-Criteria Decision- } \\
\text { Making (MCDM). }\end{array}$ & $\begin{array}{l}\text { With their urban equipment, socio-cultural environment, and user diversity, the university } \\
\text { campuses emerge as critical public spaces, almost like small cities. Every individual living } \\
\text { in the city and having the opportunity to interfere with daily life in public spaces has the } \\
\text { right to benefit equally from the possibilities and options provided by the town in which } \\
\text { they live. The concept of Inclusive Design emerged to ensure that people can access existing } \\
\text { opportunities as equally as possible. Decision-making processes in architectural design } \\
\text { include many stages. These processes are trying to find the best solution, called the solution } \\
\text { alternatives of the problem to be solved, and choosing among these alternatives. In this } \\
\text { paper, an integrated Consistent Fuzzy Preference Relations (CFPR) - Grey Relational } \\
\text { Analysis (GRA) methodology is applied to prioritize campus components according to the } \\
\text { inclusive design principles. The results of this hybrid methodology were compared with the } \\
\text { results of the CFPR and GRA methodologies. In conclusion, the ranking of campus } \\
\text { components is obtained, and the most crucial campus component is selected for designing } \\
\text { inclusive university campuses. }\end{array}$ \\
\hline
\end{tabular}

\section{Introduction}

The public spaces of the city, where the social relations of the members of the society are intense, have an important place in the urban development. Along with the cultural, economic, and technological conditions in constant change and development, the understanding, need, and use of public space are also affected by this situation.

Since the city's public spaces have an important place in urban development, they should be shaped according to needs. Since the campuses function as small cities thanks to their facilities and social environment, they emerge as important public spaces. Campus areas affect our attitudes about education and should be shaped according to needs and designed to include all campus users.

Every man or woman dwelling inside the metropolis and having the opportunity to interfere with daily existence in public spaces has the right to gain equally from the possibilities and options supplied through the city wherein they stay. The idea of inclusive design has emerged to ensure that humans can access present opportunities equally as feasible [1]. It's far defined because of designing merchandise and environments that many people can use in many feasible situations [2].

The climate on a college campus is a term used to discuss how individuals and groups experience the environment in

* Corresponding Author: Sahika Ozdemir

E-mail address: sahika.ozdemir@izu.edu.tr

Received: 23 June 2021; Revised: 03 July 2021; Accepted:

https://doi.org/10.52547/crpase.7.3.2363

Please cite this article as: S. Ozdemir, K.G. Nalbant, Y. Ozdemir, Evaluating Campus Components According To The Inclusive Design Principles Using An Integrated Consistent Fuzzy Preference Relations And Grey Relational Analysis Methodology, Computational Research Progress in Applied Science \& Engineering, CRPASE: Transactions of Civil and Environmental Engineering 7 (2021) 1-5, Article ID: 2363. 
the campus community. It is a general term that summarizes the organization's inclusiveness dynamics and the extent to which various stakeholders are felt to be included or excluded from the environment. As conversations about climate naturally deal with different groups' natural and perceived realities, this notion always involves social identities defined in the race, ethnicity, gender, sexuality, disability, and a complete spectrum [3].

The campus climate results in the diversity of individuals from different backgrounds. On the other hand, climate refers to the experience of individuals and groups on campus and the nature and extent of interaction between these various groups and individuals. In other words, campus climate is an essential component of a comprehensive plan for diversity. To lay the foundation for a learning community, the academy's primary mission should be to create an environment fostering diversity and understanding the difference [4].

Inclusive design principles can also be applied to specific teaching materials, facilities, and strategies (such as lectures, classroom discussions, group work, web-based teaching, laboratories, fieldwork, and demonstrations). The inclusively designed curriculum provides students with various abilities, disabilities, ethnicities, language skills and learning styles, and multiple tools for expression and participation. Below are examples of teaching using inclusion principles. It is organized under eight performance indicator categories with a target statement for each [5].

Class climate; Adopting practices that reflect high values of both diversity and inclusion; Seek student input to discuss the syllabus, disability-based, and other special learning needs.

Interaction; To encourage regular and effective interactions between students and faculty and ensure that communication methods are accessible to all participants; to enable students to do group work.

Physical environment and products; Ensuring that facilities, activities, materials, and equipment are physically accessible and usable by all students, all possible student features are addressed with safety considerations; to improve safety procedures for all students, including blind, deaf, or wheelchair users.

Teaching methods; To use accessible teaching methods that are accessible to all learners; where possible, enabling students to choose from multiple options for learning, lectures, collaborative learning options, real-time activities, internet-based communication, courseware, fieldwork, etc., to think about such matters.

Information resources and technology; Ensuring that course materials, notes, and other sources of information are engaging, flexible, and accessible to all students; select printed materials and arrange an early curriculum, alternative formats such as books in audio format to allow students to start reading materials and working on assignments before class begins.

Feedback; Provide specific feedback, allowing students to submit their significant projects for feedback before the final project is finished.
Evaluation; Regularly assess student progress and adjust instructions accordingly, using multiple accessible methods and tools, evaluate group performance and individual success.

Residential; Making plans for students who do not meet their needs with educational design; know campus protocols for acquiring materials in alternative formats, rescheduling classroom spaces, and arranging other accommodations for the disabled.

Architectural design is defined as a decision-making action in responding to spatial needs and the user's needs and creating a solution to a problem. Decision-making processes in architectural design include many stages. These processes are trying to find the best solution, called the solution alternatives of the problem to be solved, and choosing among these alternatives [4]. While the use of decision-making methods in engineering is dominant, their use in architecture is becoming increasingly common. These methods can be listed as reaching an optimum solution with the designed alternatives, evolving the design process, allowing recycling, controlling these processes, and creating data for future designs.

There are many studies about the CFPR method in the literature. Ozdemir et al. [6] determined personnel selection criteria and prioritized these criteria by CFPR. Cheng et al. [7] developed CFPR based ANP method to find the preference-weights of the criteria for R\&D Project Selection. $\mathrm{Lu}$ et al. [8] used CFPR for location selection of an LNG Bunkering Port in Korea. Ozdemir et al. [9] evaluated campus components according to the inclusive design principles using CFPR and FANP methodologies. Ozdemir and Nalbant [10] integrated CFPR and Analytic Hierarchy Process (FAHP) methodologies for personnel selection.

There can be found many studies about the GRA method in the literature. Chang et al. [11] used the Grey relational grade deduced by Grey theory [12] to establish a complete and accurate evaluation model for determining who the best all-around athlete among all contestants is. Wang et al. [13] proposed a supplier selection framework using AHP and GRA for the supply chain management. Ozdemir et al. [14] integrated FAHP and GRA methodologies for personnel selection. Kose et al. [15] used GRA for the most livable city selection in Turkey.

There can be found many studies about the Multi-Criteria Decision-Making (MCDM) methods in the literature. Ziari et al. [16] proposed a prioritization model for the immunization of accident prone using MCDM methods and Fuzzy Hierarchy Algorithm. Nadimi et al. 117] proposed a model for ranking hotspots in rural roads using a MCDM method. Ghorbanzadeh et al. [18] used GIS-based MCDM method for a subway station site selection.

The rest of this study is arranged as follows: Hybrid methodology is explained in the 2nd section. An application of the integrated CFPR-GRA methodology in evaluating campus components according to the inclusive design principles is given in the 3rd section. Finally, Results comparison and future research directions are shown in the 4th section. 


\section{Materials and Methods}

CFPR found by Herrera-Viedma et al. [19] simplifies the pairwise comparison. Grey system theory was proposed by [12].

In the previous paper, the campus components based on inclusive design principles were evaluated using CFPR and FANP methodologies [9]. This paper applies a hybrid CFPR and GRA methodology to evaluate campus components according to the inclusive design principles. The flow diagram is shown in Figure 1 [10], [11], [20], [21], [22], [23].

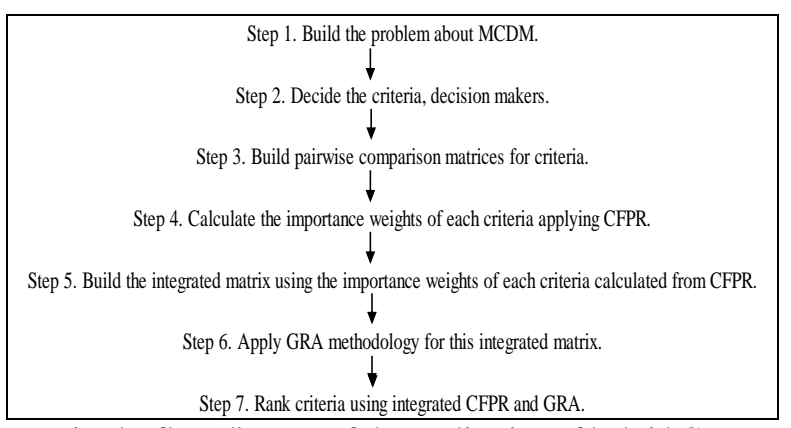

Figure 1. The flow diagram of the application of hybrid CFPRGRA methodology.

The steps of the integrated CFPR-GRA can be listed as follows:

Step 1. Build the problem about Multi-Criteria DecisionMaking (MCDM).

Step 2. Decide the criteria, decision-makers.

Step 3. Build pairwise comparison matrices for criteria.

Step 4. Calculate the importance weights of each criteria applying CFPR.

Step 5. Build the integrated matrix using the importance weights of each criteria calculated from CFPR.

Step 6. Apply GRA methodology for this integrated matrix.

Step 7. Rank criteria using integrated CFPR and GRA.

\section{Application: Evaluating the Campus Components}

In this paper, performance indicators based on inclusive design principles are studied and prioritized by applying CFPR and GRA techniques. To prioritize the eight performance indicators based on inclusive design principles referred to as criteria were identified and evaluated by three decision-makers from academia and industry. These criteria are Class Climate $(\mathrm{Cr} 1)$, Interaction (Cr2), Physical Environment and Products (Cr3), Teaching Methods (Cr4), Information Resources and Technology (Cr5), Feedback (Cr6), Evaluation (Cr7), and Residential (Cr8) (Ozdemir et al., 2020). The network of the problem is as seen in Figure 2. The arrows in this figure represent the network of the problem.

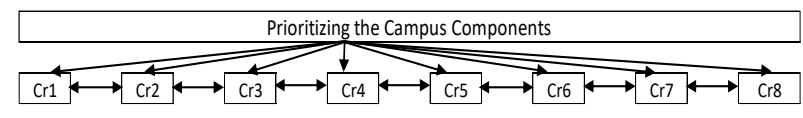

Figure 2. Network of the problem.
All decision-makers were determined the importance of criteria based on Table 1 .

Table 1. Linguistic scale.

\begin{tabular}{cc}
\hline Definition & Relative Importance \\
\hline Intermediate values & $2,4,6,8$ \\
Absolutely more important & 9 \\
Very strongly more important & 7 \\
Strongly more important & 5 \\
Moderately more important & 3 \\
Equally important & 1 \\
\hline
\end{tabular}

Firstly, for the CFPR methodology, the pairwise comparison matrix was provided by decision-maker 1 can be seen in Table 2.

Table 2. Fuzzy preference pairwise comparison matrix of

\begin{tabular}{|c|c|c|c|c|c|c|c|c|}
\hline & $\mathrm{Cr} 1$ & $\mathrm{Cr} 2$ & $\mathrm{Cr} 3$ & $\mathrm{Cr} 4$ & $\mathrm{Cr} 5$ & Cr6 & $\mathrm{Cr} 7$ & Cr8 \\
\hline $\mathrm{Cr} 1$ & 1 & 3 & & & & & & \\
\hline $\mathrm{Cr} 2$ & & 1 & 0.33 & & & & & \\
\hline $\mathrm{Cr} 3$ & & & 1 & 1 & & & & \\
\hline $\mathrm{Cr} 4$ & & & & 1 & 1 & & & \\
\hline $\mathrm{Cr} 5$ & & & & & 1 & 1 & & \\
\hline Cr6 & & & & & & 1 & 1 & \\
\hline $\mathrm{Cr} 7$ & & & & & & & 1 & 1 \\
\hline Cr8 & & & & & & & & 1 \\
\hline
\end{tabular}

Then, transformed fuzzy preference values are calculated in Table 3.

Table 3. Transformed fuzzy preference values of decision maker 1 for the criteria.

\begin{tabular}{ccccccccc}
\hline & Cr1 & Cr2 & Cr3 & Cr4 & Cr5 & Cr6 & Cr7 & Cr8 \\
\hline Cr1 & 0.5 & 0.75 & 0.5 & 0.5 & 0.5 & 0.5 & 0.5 & 0.5 \\
Cr2 & 0.25 & 0.5 & 0.25 & 0.25 & 0.25 & 0.25 & 0.25 & 0.25 \\
Cr3 & 0.5 & 0.75 & 0.5 & 0.5 & 0.5 & 0.5 & 0.5 & 0.5 \\
Cr4 & 0.5 & 0.75 & 0.5 & 0.5 & 0.5 & 0.5 & 0.5 & 0.5 \\
Cr5 & 0.5 & 0.75 & 0.5 & 0.5 & 0.5 & 0.5 & 0.5 & 0.5 \\
Cr6 & 0.5 & 0.75 & 0.5 & 0.5 & 0.5 & 0.5 & 0.5 & 0.5 \\
Cr7 & 0.5 & 0.75 & 0.5 & 0.5 & 0.5 & 0.5 & 0.5 & 0.5 \\
Cr8 & 0.5 & 0.75 & 0.5 & 0.5 & 0.5 & 0.5 & 0.5 & 0.5 \\
\hline
\end{tabular}

Preference values transformed by the transformation function for the criteria are calculated in Table 4.

Table 4. Preference values transformed by transformation function for the criteria.

\begin{tabular}{ccccccccc}
\hline & Cr1 & Cr2 & Cr3 & Cr4 & Cr5 & Cr6 & Cr7 & Cr8 \\
\hline Cr1 & 0.50 & 0.67 & 0.50 & 0.50 & 0.50 & 0.50 & 0.50 & 0.50 \\
Cr2 & 0.33 & 0.50 & 0.33 & 0.33 & 0.33 & 0.33 & 0.33 & 0.33 \\
Cr3 & 0.50 & 0.67 & 0.50 & 0.50 & 0.50 & 0.50 & 0.50 & 0.50 \\
Cr4 & 0.50 & 0.67 & 0.50 & 0.50 & 0.50 & 0.50 & 0.50 & 0.50 \\
Cr5 & 0.50 & 0.67 & 0.50 & 0.50 & 0.50 & 0.50 & 0.50 & 0.50 \\
Cr6 & 0.50 & 0.67 & 0.50 & 0.50 & 0.50 & 0.50 & 0.50 & 0.50 \\
Cr7 & 0.50 & 0.67 & 0.50 & 0.50 & 0.50 & 0.50 & 0.50 & 0.50 \\
Cr8 & 0.50 & 0.67 & 0.50 & 0.50 & 0.50 & 0.50 & 0.50 & 0.50 \\
\hline
\end{tabular}

Likewise, other matrices of the two decision-makers for all criteria are obtained. Finally, the importance weight of the 
criteria determined by three decision-makers normalized and integrated with the GRA model in Table 5.

Table 5. Integrated model's importance weight matrix.

\begin{tabular}{lllllllll}
\hline & Cr1 & Cr2 & Cr3 & Cr4 & Cr5 & Cr6 & Cr7 & Cr8 \\
\hline Cr1 & 0.17 & 0.15 & 0.17 & 0.16 & 0.15 & 0.15 & 0.15 & 0.16 \\
Cr2 & 0.12 & 0.12 & 0.12 & 0.12 & 0.12 & 0.12 & 0.12 & 0.12 \\
Cr3 & 0.17 & 0.15 & 0.17 & 0.16 & 0.15 & 0.15 & 0.15 & 0.16 \\
Cr4 & 0.14 & 0.13 & 0.14 & 0.14 & 0.13 & 0.13 & 0.13 & 0.14 \\
Cr5 & 0.11 & 0.11 & 0.11 & 0.11 & 0.11 & 0.12 & 0.12 & 0.11 \\
Cr6 & 0.08 & 0.09 & 0.08 & 0.09 & 0.10 & 0.10 & 0.10 & 0.09 \\
Cr7 & 0.08 & 0.09 & 0.08 & 0.09 & 0.10 & 0.10 & 0.10 & 0.09 \\
Cr8 & 0.14 & 0.13 & 0.14 & 0.14 & 0.13 & 0.13 & 0.13 & 0.14 \\
\hline
\end{tabular}

The expected goal for each criteria is determined in Table 6. Also, an ideal standard series is established in the last line in Table 6.

Table 6. The expected goal for each criteria.

\begin{tabular}{ccccccccc}
\hline & Cr1 & Cr2 & Cr3 & Cr4 & Cr5 & Cr6 & Cr7 & Cr8 \\
\hline Cr1 & 1.00 & 1.00 & 1.00 & 1.00 & 1.00 & 1.00 & 1.00 & 1.00 \\
Cr2 & 0.44 & 0.44 & 0.44 & 0.44 & 0.44 & 0.44 & 0.44 & 0.44 \\
Cr3 & 1.00 & 1.00 & 1.00 & 1.00 & 1.00 & 1.00 & 1.00 & 1.00 \\
Cr4 & 0.67 & 0.67 & 0.67 & 0.67 & 0.67 & 0.67 & 0.67 & 0.67 \\
Cr5 & 0.33 & 0.33 & 0.33 & 0.33 & 0.33 & 0.33 & 0.33 & 0.33 \\
Cr6 & 0.00 & 0.00 & 0.00 & 0.00 & 0.00 & 0.00 & 0.00 & 0.00 \\
Cr7 & 0.00 & 0.00 & 0.00 & 0.00 & 0.00 & 0.00 & 0.00 & 0.00 \\
Cr8 & 0.67 & 0.67 & 0.67 & 0.67 & 0.67 & 0.67 & 0.67 & 0.67 \\
Std. s. & 1.00 & 1.00 & 1.00 & 1.00 & 1.00 & 1.00 & 1.00 & 1.00 \\
\hline
\end{tabular}

The Grey relational coefficient for each personnel is calculated and shown in Table7.

Table 7. The Grey relational coefficient for each criteria.

\begin{tabular}{ccccccccc}
\hline & Cr1 & Cr2 & Cr3 & Cr4 & Cr5 & Cr6 & Cr7 & Cr8 \\
\hline Cr1 & 1.00 & 1.00 & 1.00 & 1.00 & 1.00 & 1.00 & 1.00 & 1.00 \\
Cr2 & 0.64 & 0.64 & 0.64 & 0.64 & 0.64 & 0.64 & 0.64 & 0.64 \\
Cr3 & 1.00 & 1.00 & 1.00 & 1.00 & 1.00 & 1.00 & 1.00 & 1.00 \\
Cr4 & 0.75 & 0.75 & 0.75 & 0.75 & 0.75 & 0.75 & 0.75 & 0.75 \\
Cr5 & 0.60 & 0.60 & 0.60 & 0.60 & 0.60 & 0.60 & 0.60 & 0.60 \\
Cr6 & 0.50 & 0.50 & 0.50 & 0.50 & 0.50 & 0.50 & 0.50 & 0.50 \\
Cr7 & 0.50 & 0.50 & 0.50 & 0.50 & 0.50 & 0.50 & 0.50 & 0.50 \\
Cr8 & 0.75 & 0.75 & 0.75 & 0.75 & 0.75 & 0.75 & 0.75 & 0.75 \\
\hline
\end{tabular}

The Grey relational grade for each personnel is found and shown in Table 8.

Table 8. The Grey relational grade for each personnel.

\begin{tabular}{cccccccc}
\hline Cr1 & Cr2 & Cr3 & Cr4 & Cr5 & Cr6 & Cr7 & Cr8 \\
1 & 0.64 & 1 & 0.75 & 0.6 & 0.5 & 0.5 & 0.75 \\
\hline
\end{tabular}

From Table 8, the ranking of inclusive design principles is obtained as $\mathrm{Cr} 1=\mathrm{Cr} 3>\mathrm{Cr} 4=\mathrm{Cr} 8>\mathrm{Cr} 2>\mathrm{Cr} 5>\mathrm{Cr} 6=\mathrm{Cr} 7$. Given these results, it is fair to say that selecting $\mathrm{Cr} 1$ or $\mathrm{Cr} 3$ is the most reasonable outcome, followed by the others.

\section{Discussion}

With their urban equipment, socio-cultural environment, and user diversity, university campuses emerge as critical public spaces, almost like small cities. Campus areas influence our attitudes about education. While very few designers today embrace human-centered design and do campus design, it needs to be included in the whole process. Human-centered designs start by considering the needs of students and educators, who are the primary campus users, and enable the field to support learning transformation.

The inclusive environment ensures equal opportunities and participation of all. Inclusive design is an architectural issue and a political, economic, social, and technological issue. Although the campus physical environment characteristics theoretically encompass all possibilities, the layout, location, and arrangement of space and facilities may make some behaviors more likely and more likely than others. Campuses create a whole with their work, education, accommodation, recreation, sports units, green areas, and circulation areas.

The decision-making process in design is a process that follows problem-solving actions and chooses among solution alternatives. While the use of systematic methods developed for decision-making in the field of engineering finds broad application areas, it is seen that the applications in the field of architecture are more limited. This is because the actions taking place in the designer's mind cannot be fully explained, and the activities cannot be observed in the architectural design field, where individual processes and subjective evaluations are dominant. For this reason, for a model to help decision-making in architectural design be accepted, it is of great importance that the developed model effectively evaluates qualitative data and quantitative data. The primary goal of using the multi-criteria decision-making method within the scope of the developed model is; to assist decision-makers in systematically evaluating possible alternatives by reducing uncertainty and complexity in the decision-making process.

In the previous study [9], multi-criteria decision-making techniques, CFPR, and Fuzzy Analytic Network Process (FANP) methods were applied for the evaluation of campus components using triangular (in FANP method) fuzzy numbers.

In the previous paper, the campus components based on inclusive design principles were evaluated using Consistent Fuzzy Preference Relations (CFPR) and Fuzzy Analytic Network Process (FANP) [9]. In this paper, the hybrid CFPR-GRA method is used to prioritize campus components according to inclusive design principles.

In this study, as an extension of CFPR and FANP results, a hybrid CFPR and GRA methodology is used for the evaluation with the same data. The result of this hybrid method is compared with previous results. The CFPR method is used to determine the weight of criteria specified by experts in selecting campus components. Then, the GRA method is used to obtain the ranking of these criteria.

The results of the hybrid CFPR-GRA methodology and the comparison with the results of CFPR and FANP methodologies are given in Table 9. According to the results, the ranking is obtained as $\mathrm{Cr} 1=\mathrm{Cr} 3>\mathrm{Cr} 4=\mathrm{Cr} 8>\mathrm{Cr} 2>\mathrm{Cr} 5>\mathrm{Cr} 6=\mathrm{Cr} 7$ for hybrid CFPR GRA methodology and as $\mathrm{Cr} 1=\mathrm{Cr} 3>\mathrm{Cr} 4=\mathrm{Cr} 8>\mathrm{Cr} 2>\mathrm{Cr} 5>\mathrm{Cr} 6=\mathrm{Cr} 7$ for $\mathrm{CFPR}$ methodology and as $\mathrm{Cr} 3>\mathrm{Cr} 4=\mathrm{Cr} 8>\mathrm{Cr} 1=\mathrm{Cr} 2=\mathrm{Cr} 5>\mathrm{Cr} 6=\mathrm{Cr} 7$ for FANP methodology. Given these results, the most important design component as "Physical environment and products" (Cr3) is the most reasonable outcome, followed by the others. Furthermore, the least important design components are "Feedback" (Cr6) and "Evaluation" (Cr7). It 
is recommended that this ranking be taken into account when designing inclusive university campuses.

Table 9. Comparison of the results of all methods.

\begin{tabular}{llccccc}
\hline & \multicolumn{3}{c}{ Weights } & \multicolumn{3}{c}{ Normalized Values } \\
\cline { 2 - 7 } $\begin{array}{l}\text { Hybrid } \\
\text { method }\end{array}$ & & $\begin{array}{c}\text { FANP method } \\
\text { method }\end{array}$ & $\begin{array}{c}\text { Hybrid } \\
\text { method }\end{array}$ & CFPR method & $\begin{array}{c}\text { FANP } \\
\text { method }\end{array}$ \\
\hline Cr1 & $\mathbf{1 . 0 0}$ & $\mathbf{0 . 1 6}$ & 0.13 & $\mathbf{1 7 . 4 1 \%}$ & $\mathbf{1 6 \%}$ & $9.66 \%$ \\
Cr2 & 0.64 & 0.12 & 0.13 & $11.19 \%$ & $12 \%$ & $9.66 \%$ \\
Cr3 & $\mathbf{1 . 0 0}$ & $\mathbf{0 . 1 6}$ & $\mathbf{0 . 3 5}$ & $\mathbf{1 7 . 4 1 \%}$ & $\mathbf{1 6 \%}$ & $\mathbf{2 6 . 7 9 \%}$ \\
Cr4 & 0.75 & 0.13 & 0.20 & $13.06 \%$ & $13 \%$ & $15.70 \%$ \\
Cr5 & 0.60 & 0.11 & 0.13 & $10.45 \%$ & $11 \%$ & $9.66 \%$ \\
Cr6 & 0.50 & 0.09 & 0.08 & $8.71 \%$ & $9 \%$ & $6.41 \%$ \\
Cr7 & 0.50 & 0.09 & 0.08 & $8.71 \%$ & $9 \%$ & $6.41 \%$ \\
Cr8 & 0.75 & 0.13 & 0.20 & $13.06 \%$ & $13 \%$ & $15.70 \%$ \\
\hline
\end{tabular}

MCDM is a well-known and widely applied decisionmaking branch. In this study, the campus component selection problem was solved according to the inclusive design principles. The methodology can be used for designing inclusive university campuses.

\section{Conclusions}

The main contribution of this paper is the first-time usage of the hybrid approach, including CFPR and GRA methodologies in prioritizing campus components according to the inclusive design principles.

The results were compared according to the CFPR-GRA hybrid method, the CFPR method, and the FANP method in this study. Considering the three methods used in this study, "Physical environment and products" (Cr3) was chosen as the most important design component and the least important design components were selected as "Feedback" (Cr6) and "Evaluation" (Cr7).

For future researches, the selection problem could be solved by other MCDM methods, and intelligent software to calculate solutions automatically could be developed.

\section{Conflict of Interest Statement}

The authors declare no conflict of interest.

\section{References}

[1] R. Mace, Universal Design, Barrier free environments for everyone. Designers West, Los Angeles, 1985.

[2] M. Prellwitz, Playgrounds Accessibility and Usability for Children with Disabilities. Luleå University of Technology Department of Human Work Sciences, PhD Thesis, Sweden, 2007.

[3] D.A. Williams, Campus Climate \& Culture Study. Florida Gulf Coast University, USA, 2010.

[4] S. Ozdemir, An Assessment Tool Proposal for Making University Campuses Suitable for the Inclusive Design Concept. Y1ldiz Technical University, Institute of Science, PhD Thesis, Istanbul, 2019.

[5] S. Burgstahler, Equal access: Universal design of instruction. DO-IT, University of Washington, 2007. http://www.washington.edu/doit/Brochures/Academics/equal _access_udi.html, 18 April 2017.

[6] Y. Ozdemir, K.G. Nalbant, \& H. Basligil, Evaluation of personnel selection criteria using Consistent Fuzzy Preference Relations, International Journal of Management Science 4 (2017) 76-81.
[7] C.H. Cheng, J.J. Liou, \& C.Y. Chiu, A consistent fuzzy preference relations based ANP model for $R \& D$ project selection, Sustainability 9 (2017) 1352.

[8] W. Lu, J.H. Seo, \& G.T. Yeo, Location Selection of an LNG Bunkering Port in Korea, Journal of Korea Trade 23 (2019) 59-75.

[9] S. Ozdemir, Y. Ozdemir, K.G. Nalbant, Evaluating Campus Components According to the Inclusive Design Principles Using CFPR and FANP Methodologies. Academic Researches in Architecture, Planning and Design Sciences, ed. Prof. Latif Gurkan Kaya, Ph.D., Platanus Publishing, ISBN: 978-6257767-71-2, (October 2020).

[10] Y. Ozdemir, K.G. Nalbant, Personnel Selection for Promotion using an Integrated Consistent Fuzzy Preference RelationsFuzzy Analytic Hierarchy Process Methodology: A Real Case Study, Asian Journal of Interdisciplinary Research 3 (2020) 219-236.

[11] C.L. Chang, C.H. Tsai, L. Chen, Applying Grey Relational Analysis to the Decathlon evaluation model, International Journal of The Computer, The Internet and Management 11 (2003) 54-62.

[12] J.L. Deng, Introduction to Grey System. Journal of Grey System 1 (1989) 1-24.

[13] T.K. Wang, Q. Zhang, H.Y. Chong, \& X. Wang, Integrated supplier selection framework in a resilient construction supply chain: An approach via analytic hierarchy process (AHP) and grey relational analysis (GRA), Sustainability 9 (2017) 289.

[14] Y. Ozdemir, K.G. Nalbant, H. Basligil, Personnel Selection for Promotion Using an Integrated Fuzzy Analytic Hierarchy Process-Grey Relational Analysis Methodology: A Real Case Study, Anadolu University Journal of Science and Technology A - Applied Sciences and Engineering (AUJST-A) 19 (2018) 278-292.

[15] E. Kose, D. Vural, \& G. Canbulut, The most livable city selection in Turkey with the grey relational analysis, Grey Systems: Theory and Application, 2020.

[16] H. Ziari, A. Amini, A. Saadatjoo, S.M. Hosseini, \& V.N.M. Gilani, A prioritization model for the immunization of accident prone using multi-criteria decision methods and fuzzy hierarchy algorithm, Computational Research Progress in Applied Science \& Engineering (CRPASE) 3 (2017).

[17] N. Nadimia, S.S.N. Alavia, A.H.Z. Mirhosseinia, \& A.M. Amirib, Proposing a Model for Ranking Hotspots in Rural Roads Using a Multi-criteria Decision-making Method, Computational Research Progress in Applied Science \& Engineering (CRPASE) 3 (NCHTE 2017).

[18] M. Ghorbanzadeh, M. Effati, M. Gilanifar, \& E.E. Ozguven, Subway station site selection using GIS-based multi-criteria decision-making: a case study in a developing country, Comput. Res. Prog. Appl. Sci. Eng 6 (2020) 60-69.

[19] E. Herrera-Viedma, F. Herrera, F. Chiclana, \& M. Luque, M. Some issues on consistency of fuzzy preference relations, European journal of operational research 154 (2004) 98-109.

[20] A. Jafarnejad, M. Ebrahimi, M.A. Abbaszadeh, \& S.M. Abtahi, Risk management in supply chain using consistent fuzzy preference relations, International Journal of Academic Research in Business and Social Sciences 4 (2014) 77.

[21] P. Pitchipoo, P. Venkumar, S. Rajakarunakaran, Grey Decision Model for Supplier Selection in Process Industry, International Journal of Operations System and Human Resource Management 1 (2011) 61-66.

[22] H.H. Wu, The introduction of Grey Analysis. Taipei: Gauli Publishing Co., 1996.

[23] H.H. Wu, The method and application of Grey Decisions. Chang-Hwa: Chien-Kuo Institute of Technology, 1998. 